В. С. Сторчак, В. М. Руденко

Льотна академія Національного авіаційного університету, Кропивницький, Україна

\title{
ОЦІНКА ЕФЕКТИВНОСТІ ТРЕНАЖЕРІВ ДЛЯ ПІДГОТОВКИ ДИСПЕТЧЕРІВ УПРАВЛІННЯ ПОВІТРЯНИМ РУХОМ
}

\begin{abstract}
Предметом вивчення статті є аналіз способів та засобів забезпечення підвищення рівня професійної підготовки диспетчерів управління повітряним рухом за рахунок використання тренажерів у навчальному процесі. Метою роботи $\epsilon$ визначення порядку оцінки ефективності тренажерів для підготовки диспетчерів управління повітряним рухом. Задача - визначити ефективність використання тренажерів у навчальному процесі, а також відповідність даного тренажера вимогам підготовки диспетчерів управління повітряним рухом. А саме, здатність вирішувати конкретні завдання тренажерної підготовки і забезпечити необхідний рівень компетентності диспетчера управління повітряним рухом. Висновки - застосування такого підходу дозволяє визначити, чи відповідає даний тренажер вимогам досягнення диспетчерами управління повітряним рухом необхідних компетентностей, зазначених у вимогах кваліфікаційної характеристики, і оцінити ефективність тренажера за результатами навчання на ньому.
\end{abstract}

Кл юч ов і сл ов а: диспетчер управління повітряним рухом, оцінка ефективності, тренажер, тренажерний комплекс, кваліфікаційна характеристика, компетентність..

\section{Вступ}

Постановка задачі. Підтримка професійно важливих якостей і їх відновлення за допомогою тренажерної підготовки - це один з основних видів підготовки диспетчера управління повітряним рухом (оператора), що дозволяє закріпити й поглибити отримані знання, придбати навички й уміння в управлінні польотами в будь яких умовах навігаційної обстановки.

Від того, наскільки продуманий зміст такої підготовки, як організований і проведений навчальний процес, буде залежати рівень професійної майстерності та безпека польотів. Зазначені обставини викликають необхідність уніфікації проведення тренажерної підготовки на всіх рівнях, починаючи 3 навчального закладу закінчуючи місцем постійної роботи фахівця (рис. 1).

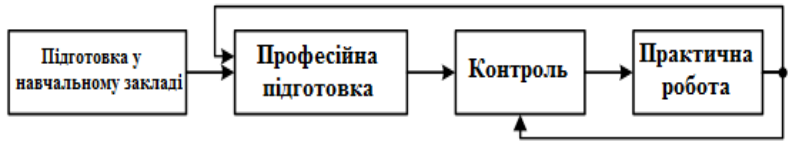

Рис. 1. Процес підготовки диспетчера управління повітряним рухом

Основним завданням застосування тренажерів в навчанні диспетчерів УПР є прищеплення певних знань, умінь і навичок, а також їх автоматизована або автоматична перевірка і оцінка їх дій. Незалежно від рівня кваліфікації, основні вимоги до диспетчерам УПР полягають в наступному [1 - 3]:

- вироблення навичок правильного прийняття управлінських рішень в умовах складної інформаційного середовища;

- вироблення навичок і умінь операторської

роботи $з$ обладнанням;

- вміння застосовувати правила і процедури для управління польотами і приймати рішення як в штатних, так і в позаштатних ситуаціях.

Вироблення навичок управління польотами $\epsilon$ найважливішим завданням тренажерної підготовки. Невід'ємною складовою частиною такої підготовки $\epsilon$ вправи, сценарії яких поєднують у собі функціональні можливості тренажера і методику, яка застосовується інструктором для вирішення поставлених в програмі навчання завдань.

Тому тренажер для підготовки диспетчерів УПР повинен бути ефективним не тільки 3 функціональної, але і з методологічної та економічної точок зору, тобто він повинен забезпечувати досягнення показників навчання за наступними критеріями $[1$, $4,5]$ :

- повнота охоплення навчальних завдань, орієнтованих на кожного оператора;

- відповідність навчальної програми цілям і змісту курсу підготовки диспетчерів УПР;

- витрати на тренажерне забезпечення підготовки.

Перераховані критерії дозволяють оцінити ефективність тренажерної підготовки диспетчерів УПР, порівняти тренажери і забезпечити оцінку динаміки їх розвитку $[5,6]$.

Ефективність застосовуваного тренажера $є$ одним з основних показників, що визначають ефективність як самого навчання, так і підсумкової оцінки набутих навичок та вмінь.

Тому актуальна розробка методики оцінки ефективності тренажерів для підготовки диспетчерів управління повітряним рухом.

Аналіз літератури. Оцінка ефективності застосування в навчальному процесі тренажерів як функція їх якості розглядалася в роботах таких вчених, як: Недзельський I.I., Шукшунов В.С., Кобзарев Ю. та ін. [7-10]. У цих роботах запропоновані оцінки ефективності, засновані на аналізі однієї або декількох окремих характеристик, не враховують методичних і організаційних особливостей використання тренажерів у навчальному процесі, тобто їх дидактичних можливостей.

В роботі Ралля В. Ю. розглядалася оцінка економічної ефективності навчання 3 використанням тренажерів на основі порівняння годинної вартості експлуатації тренажера і моделюється їм реальної техніки, яка застосовується в навчальних цілях [11]. 
Крім того, також розглядався коефіцієнт ефективності тренування, що показує, якій кількості годин використання в навчальних цілях реальної техніки відповідає одна година тренування на тренажеpi.

В роботі Айзінова С. Д. розроблена методика оцінки ефективності спеціалізованих комп'ютерних морських тренажерів і створення на іiі основі експертної системи вибору найбільш ефективного (оптимального) тренажерного комплексу, що забезпечує максимальну ефективність процесу навчання, а також проведення аналізу тренажерів для підготовки морських фахівців [12].

Однак в літературі недостатньо розглянуті питання оцінки ефективності тренажера для підготовки диспетчерів управління повітряним рухом.

Відомі оцінки ефективності тренажерів або грунтуються тільки на економічних показниках, що не враховують ефективність використання тренажерів у навчальному процесі, або використовують для порівняння окремі показники.

Особливо слабо вивчені дидактичні характеристики тренажерів, що визначають ефективність тренажерного комплексу як технічного засоби навчання.

Метою статті $\epsilon$ визначення порядку оцінки ефективності тренажерів для підготовки диспетчерів управління повітряним рухом (операторів).

\section{Результати досліджень}

Для визначення ефективності використання тренажера в навчальному процесі необхідно враховувати вимоги кваліфікаційних характеристик і факторів, що визначають відповідність тренажера конкретним завданням підготовки диспетчерів УПР [5, 6, $12]$.

Для цього введемо показник адекватності кваліфікаційної характеристики (F) і сформуємо склад факторів (K), що впливають на оцінку адекватності та ефективності використання тренажера в процесі підготовки диспетчера УПР [5, 6, 12].

Таким чином, запропоновані оцінки тренажерів визначають відповідність даного тренажера вимогам підготовки диспетчера УПР. А саме, здатність вирішувати конкретні завдання тренажерної підготовки і забезпечити необхідний рівень компетентності диспетчера УПР.

Для оцінки ефективності тренажера необхідно визначити:

1. Які завдання і вправи можуть бути відпрацьовані на тренажері?

2. Які компетентності, із зазначених у кваліфікаційній характеристиці диспетчера УПР, можуть бути забезпечені тренажером?

3. Які функції обладнання АРМ реалізовані в тренажері?

4. Які методи оцінювання реалізовані в тренажері?

Розглянемо оцінку адекватності тренажера для підготовки диспетчерів УПР.

Адекватність кваліфікаційній характеристиці визначається чотирма факторами.
1. Повнота вирішуваних завдань $K_{1}$.

Повнотою завдань є відношення кількості завдань, що забезпечуються тренажером до повного числа завдань курсу професійної підготовки диспетчера УПР.

$$
K_{1}=\frac{K_{p_{1}}}{K_{\text {необх }}}
$$

де $K_{p_{1}}$ - кількість завдань, які дозволяє реалізувати тренажер;

$K_{\text {необх }}$ - кількість завдань, які необхідно виконати диспетчеру УПР з повного числа завдань (компетентностей) кваліфікаційної характеристики і курсу професійної підготовки.

Першим слід розглянути той варіант, коли тренажер дозволяє вирішувати всі завдання, тобто забезпечується повнота їх вирішення, а значить, $K_{1}=1$.

Другий варіант - тренажер дозволяє вирішувати частину поставлених програмою завдань (розраховується, скільки завдань 3 необхідного числа тренажер дозволяє вирішувати), $0 \leq K_{1} \leq 1$.

Третій можливий варіант - тренажер не дозволяє вирішити жодної задачі $з$ кваліфікаційної характеристики фахівця, $K_{1}=0$.

\section{2. Конфігурація тренажера $K_{2}$.}

Відповідність конфігурації тренажера завданням тренажерної підготовки. Конфігурація визначається як сукупність програмного забезпечення та апаратних засобів, що забезпечують рішення певного переліку завдань.

Стосовно до тренажерів для підготовки диспетчерів УПР цей параметр визначає можливість навчання процедурам, методикам і практики управління ПС при вирішенні різних завдань. Таким чином, фактор конфігурації визначає можливість створення тренажером інтегрованого інформаційного середовища для відпрацювання дій в реальному чаci.

$$
K_{2}=\frac{K_{p_{2}}}{K_{\text {необх }}}
$$

де $K_{p_{2}}$ - кількість конфігураційних елементів АРМ об'єкта АСУ, які дозволяє реалізувати тренажер (пультове обладнання, інформаційна модель, зв'язок, засоби відображення та ін.);

$K_{\text {необх }}$ - кількість конфігураційних елементів АРМ реального об'єкта АСУ.

Якщо $K_{2}=0$, то конфігурація тренажера не відповідає вимогам забезпечення кваліфікаційної характеристики.

Якщо $0<K_{2}<1$, то конфігурація тренажера дозволяє забезпечити відпрацювання завдань для придбання необхідних умінь і навичок в тій чи іншій мірі. 
3. Ступінь забезпечення вимог кваліфікаційної характеристики $K_{3}$.

Даний фактор характеризує те, наскільки в кількісному вираженні виконані вимоги щодо прищеплювання навичок, умінь і знань в тренажері.

$$
K_{3}=K_{p_{3}} / K_{\text {необ } x_{3}},
$$

де $K_{p_{3}}$ - кількість компетенцій зазначених у кваліфікаційній характеристиці, які забезпечуються тренажером;

$K_{\text {необх }}$ - кількість всіх компетенцій зазначених у кваліфікаційній характеристиці.

При проведенні оцінки фактору $K_{3}$ «Ступінь забезпечення вимог кваліфікаційної характеристики» слід врахувати, що чим вище результат підсумкової оцінки компетентності після закінчення навчання, тим вище ефективність тренажера.

Тоді маємо:

$K_{3}=1$ - тренажер повністю забезпечує рівень компетентності учня; $K_{3}=0$ - тренажер не забезпечує рівень компетентності учня; $0<K_{3}<1$ - тренажер частково забезпечує рівень компетентності учня.

\section{4. Якість оцінки діяльності оператора $K_{4}$.}

При оцінці фактору $K_{4}$ повинні враховуватися положення керівних документів:

- тренажер повинен забезпечувати можливість перевірки досягнення рівня підготовки диспетчером УПР;

- тренажер повинен мати встановлені і явно виражені критерії оцінювання з тим, щоб забезпечити надійність і одноманітність оцінки;

- тренажер повинен забезпечувати можливість тому, кого навчають продемонструвати здатність виконувати завдання безпечно і ефективно;

- тренажер здатний задовольняти конкретним цілям оцінки і навчання.

$$
K_{4}=K_{p_{4}} / K_{\text {необ } x_{4}},
$$

де $K_{p_{4}}$ - кількість критеріїв оцінки дій оператора (час виконання операцій, алгоритм дій, правильність виконання операцій та ін.), які забезпечуються тренажером; $K_{\text {необ } x_{4}}$ - кількість всіх критеріїв оцінки дій оператора, зазначених в курсі професійної підготовки.

Отже, якщо тренажер має автоматичні або автоматизовані засоби оцінки діяльності оператора, що використовують чіткі критерії і методику оцінювання, то $K_{1}=0$.

Якщо тренажер не дозволяє здійснити оцінку діяльності оператора, то $K_{4}=0$.

Якщо тренажер не володіє автоматичними або автоматизованими засобами оцінки діяльності оператора, але дозволяє здійснити оцінку знань, умінь, навичок учня, коли інструктор застосовує критерії та методику оцінки, то $0<K_{4}<1$.
Для оцінки ефективності тренажера необхідно об'єднати приватні фактори і показник ефективності тренажера.

Як показник ефективності визначимо функціонал Q, що залежить від приватних чинників $K_{i}$

$$
Q=Q\left(W_{i} \cdot K_{i}\right), i=1 \quad M,
$$

де $\mathrm{M}$ - число факторів показника адекватності кваліфікаційної характеристики;

$W_{i}$ - вагові коефіцієнти, що враховують важливість окремих факторів в загальній оцінці ефективності.

Вагові коефіцієнти приймають значення від одиниці (дуже важливий параметр) до нуля (параметр не враховується). Вибір значень $W_{i}$ залежить від призначення системи.

Таким чином, для визначення ефективності тренажера необхідно ранжувати параметри $K_{1} \quad K_{n}$.

Слід зазначити, що наведені нами чотири фактори показника адекватності кваліфікаційної характеристики тренажера не рівнозначні. Кожен 3 них має певне вагове значення, що відрізняє один від іншого.

Таким чином, в разі, якщо показник Q (ефективність тренажера) дорівнює одиниці або потрапляє в інтервал значень 0,8-1,0, то тренажер можна віднести до найвищого класу відповідності, що означає наступне:

1) тренажер відповідає цілям і задачам підготовки, на ньому можна забезпечити навчання і оцінку за всіма компетентностями, зазначеним у кваліфікаційній характеристиці фахівця;

2) тренажер володіє достатньою і необхідною функціональною повнотою, реалізує всі важливі функції обладнання АРМ і забезпечує виконання всього необхідного переліку завдань навчання, тобто має повний набір баз даних, необхідних для виконання функціональних завдань і завдань, які формують вихідну інформацію.

У разі, якщо показник Q потрапляє в інтервал значень 0-0,5 то тренажер можна віднести до нижчого класу відповідності, що означає наступне:

1) тренажер не в повній мірі відповідає цілям i задачам підготовки, 3 його допомогою неможливо повністю забезпечити необхідну кваліфікаційну характеристику;

2) тренажер не володіє достатньою і необхідною функціональної повнотою, тобто не забезпечує виконання всього необхідного переліку завдань навчання, при цьому набір баз даних необхідної для виконання функцій і завдань інформації відсутній або не актуалізований;

\section{Висновки}

Застосування такого підходу дозволяє визначити, чи відповідає даний тренажер вимогам досягнення диспетчерами управління повітряним рухом необхідних компетентностей, зазначених у вимогах кваліфікаційної характеристики, і оцінити ефективність тренажера за результатами навчання на ньому. 
СПИСОК ЛІТЕРАТУРИ

1. Тренажерные комплексы и тренажеры: технологии разработки и опыт эксплуатации / [В.Е. Шукшунов, В.В. Циблиев, С.И. Потоцкий и др.]; под ред. В.Е. Шукшунова. - М.: Машиностроение, 2005. - 383 с.

2. Образцов П.И. Формирование компетентности у военных специалистов в ВВУЗЕ средствами профессиональноориентированной технологии обучения / П.И. Образцов, А.И. Козачок; Академия ФСО России. - Орел, 2005. - 164 с. - Деп. в ВИНИТИ 15.06.05, №846-В2005.

3. Павленко М.А. Принципы построения перспективных тренажерных систем подготовки операторов АСУ динамическими объектами / М.А. Павленко, А.И. Тимочко, Г.С. Степанов, В.Г. Чернов // Сучасні інформаційні технології у сфері безпеки та оборони. - К., 2014. - Вып. 1 (19). - С. 112-117.

4. Шукшунов В.Е. Опыт и новые концепции разработки тренажных комплексов для подготовки космонавтов / В.Е. Шукшунов, С.И. Потоцкий, В.В. Фоменко, Г.В. Безруков // Авикосмическое приборостроение. - 2003. - № 9. C. $59-64$.

5. Загретдинов И.Ш. Обеспечение комплексной адекватности тренажеров для электроэнергетики - основа безаварийной работы оперативного персонала / И.Ш. Загретдинов, С.И. Магид, С.В. Мищеряков, Л.В. Сысоева, Е.П. Архипова. - М.: Апарт, 2003. - 32 с.

6. Сазонов А.Е. Методические оценки эффективности обучения на тренажерах / А.Е. Сазонов, С.Д. Айзинов //Эксплуатация морского транспорта. - СПб., 2005. - Вып. 44. - С. 38-40.

7. Недзельский И.И. Морские навигационные тренажеры: проблемы выбора / И.И. Недзельский. - СПб.: ГНЦ РФЦНИИ «Электроприбор», 2002. - 220 с.

8. Шукшунов В.Е. Тренажерные системы / В.Е. Шукшунов, Ю.А. Бакулов, В.Н. Григоренко. - М.: Машиностроение, 1981. $-256 \mathrm{c}$.

9. Кобзарев Ю. Комплексный тренажер по кораблевождению / Ю. Кобзарев, Б. Головань // Морской сборник. - 1993. № 5. - C. 27-29.

10. Коваленко А.А. Сучасний стан та тенденції розвитку комп'ютерних систем об'єктів критичного застосування / А.А. Коваленко, Г.А. Кучук // Системи управління, навігації та зв'язку. - Полтава . ПНТУ, 2018. - Вип. 1(47). C. $110-113$.

11. Ралль В.Ю. Тренажеры и имитаторы ВМФ /В.Ю. Ралль, О.Л Макарьев, В.С. Поляков. - М.: ВИ, 1969. -215 с.

12. Айзинов С.Д. Теоретические и методические основы создания экспертной системы по оценке эффективности морских тренажёров (на примере тренажёров ГМССБ): дис. ... канд. тех. наук : 05.12.13 / Айзинов Сергей Дмитриевич. СПб., 2007. - 168 c.

Рецензент: д-р техн. наук, проф. О. І. Тимочко, Харківський національний університет Повітряних Сил імені Івана Кожедуба, Харків. Received (Надійшла) 01.11.2018 Accepted for publication (Прийнята до друку) 16.01.2019

\section{Оценка эффективности тренажеров для подготовки диспетчеров управления воздушным движением \\ В. С. Сторчак, В. Н. Руденко}

Предметом изучения статьи является анализ способов и средств обеспечения повышения уровня профессиональной подготовки диспетчеров управления воздушным движением за счет использования тренажеров в учебном процессе. Целью работы является определение порядка оценки эффективности тренажеров для подготовки диспетчеров управления воздушным движением. Задача - определить эффективность использования тренажеров в учебном процессе, а также соответствие данного тренажера требованиям подготовки диспетчеров управления воздушным движением. А именно, способность решать конкретные задачи тренажерной подготовки и обеспечить необходимый уровень компетентности диспетчера управления воздушным движением. Выводы - применение такого подхода позволяет определить, соответствует ли данный тренажер требованиям достижения диспетчерами управления воздушным движением необходимых компетенций, указанных в требованиях квалификационной характеристики и оценить эффективность тренажера по результатам обучения на нем.

Ключевые слова: диспетчер управления воздушным движением, оценка эффективности, тренажер, тренажерный комплекс, квалификационная характеристика, компетентность.

\section{Evaluation of effectiveness simulators for training air traffic controllers \\ V. Storchak, V. Rudenko}

The subject of the study in the article is an analysis of ways and means to improve the determination of directions of increase of efficiency of professional preparation of air traffic controllers. The purpose is to determine the order of evaluation of the effectiveness of simulators for the preparation of air traffic controllers. The task to determine the effectiveness of the use of simulators in the educational process, as well as the compliance of this simulator with the requirements for training air traffic controllers. Namely, the ability to solve specific tasks of simulator training and to provide the necessary level of competence of the air traffic controller. Conclusion - the use of such an approach makes it possible to determine whether this simulator meets the requirements for air traffic controllers to achieve the necessary competencies specified in the qualification requirements and evaluate the simulator's effectiveness based on the results of training on it.

Keywords: air traffic controller, performance evaluation, simulator, simulator complexes, qualification characteristics, factors, competence. 